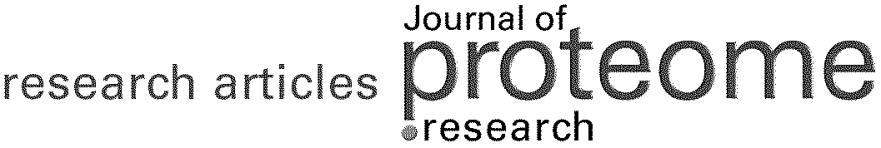

\section{Proteomic Analysis of Human Osteoblastic Cells: Relevant Proteins and Functional Categories for Differentiation}

\author{
Rodrigo D. A. M. Alves, ${ }^{\dagger}$ Marco Eijken, ${ }^{\dagger}$ Sigrid Swagemakers, ${ }^{\ddagger}$ H. Chiba, ${ }^{\$}$ Mark K. Titulaer, ${ }^{\perp}$ \\ Peter C. Burgers, ${ }^{\perp}$ Theo M. Luider,${ }^{\perp}$ and Johannes P. T. M. van Leeuwen ${ }^{*,+}$ \\ Departments of Internal Medicine, Bioinformatics and Neurology, Erasmus Medical Centre, Rotterdam, The \\ Netherlands, and Department of Pathology, Medical College, Sapporo, Japan
}

Received May 4, 2010

\begin{abstract}
Osteoblasts are the bone forming cells, capable of secreting an extracellular matrix with mineralization potential. The exact mechanism by which osteoblasts differentiate and form a mineralized extracellular matrix is presently not fully understood. To increase our knowledge about this process, we conducted proteomics analysis in human immortalized preosteoblasts (SV-HFO) able to differentiate and mineralize. We identified 381 proteins expressed during the time course of osteoblast differentiation. Gene ontology analysis revealed an overrepresentation of protein categories established as important players for osteoblast differentiation, bone formation, and mineralization such as pyrophosphatases. Proteins involved in antigen presentation, energy metabolism and cytoskeleton rearrangement constitute other overrepresented processes, whose function, albeit interesting, is not fully understood in the context of osteoblast differentiation and bone formation. Correlation analysis, based on quantitative data, revealed a biphasic osteoblast differentiation, encompassing a premineralization and a mineralization period. Identified differentially expressed proteins between mineralized and nonmineralized cells include cytoskeleton (e.g., CCT2, PLEC1, and FLNA) and extracellular matrix constituents (FN1, ANXA2, and LGALS1) among others. FT-ICR-MS data obtained for FN1, ANXA2, and LMNA shows a specific regulation of these proteins during the different phases of osteoblast differentiation. Taken together, this study increases our understanding of the proteomics changes that accompany osteoblast differentiation and may permit the discovery of novel modulators of bone formation.
\end{abstract}

Keywords: osteoblast • differentiation • proteomics • MALDI-FT-ICR-MS

\section{Introduction}

Bone is a highly specialized form of connective tissue. It is very dynamic, being continuously resorbed by osteoclasts and rebuild by osteoblasts. Osteoblasts are the bone-forming cells. They synthesize an extracellular matrix (ECM) and participate in the mineralization of this matrix. While the majority of osteoblasts enter apoptosis, the remainder enters the last stage of osteoblast differentiation becoming osteocytes. The process of osteoblast differentiation from the mesenchymal stem cell (MSC) lineage is tightly regulated and encompasses several steps. Expression of the osteoblasts-specific transcription factors Runx2 and Osterix is essential to drive MSCs toward the osteoblastic lineage. ${ }^{1-3}$ After lineage commitment, several differentiation steps take place until the formation of mature osteoblasts. These cells are characterized by the expression of the matrix proteins collagen type I, osteocalcin, osteopontin,

* To whom correspondence should be addressed: Prof. Johannes PTM van Leeuwen, Department of Internal Medicine, room 585c, Erasmus Medical Centre, P.O. Box 2040, 3000 CA Rotterdam. Tel, +31-107033405; fax, +31107032603; e-mail, j.vanleeuwen@erasmusmc.nl.

${ }^{\dagger}$ Department of Internal Medicine, Erasmus Medical Centre.

${ }^{\ddagger}$ Department of Bioinformatics, Erasmus Medical Centre.

${ }^{\S}$ Department of Pathology, Medical College.

${ }^{\perp}$ Department of Neurology, Erasmus Medical Centre. bone sialoprotein, and alkaline phosphatase (ALP), an enzyme which is believed to be involved in bone matrix mineralization. ${ }^{4}$ In vitro, human osteoblast differentiation can be triggered by glucocorticoids, ${ }^{5-7}$ in a process not completely understood. An important step toward understanding osteoblast differentiation is to characterize the osteoblast proteome during differentiation. Over the last years, proteomics technology has made tremendous progress, ${ }^{8,9}$ and nowadays, mass spectrometry (MS)-based proteomics tools can be applied to generate not only qualitative, but also quantitative information, to gain a more holistic view of biological systems. ${ }^{8}$ Several proteomic studies have been conducted to unravel the mechanisms underlying osteogenesis. ${ }^{10-14}$ Yet only a portion of the osteoblast proteome has been unveiled and additional, quantitative proteomic analyses are needed to reach the goal of capturing the full osteoblast proteome.

In this study, we aimed to extend the knowledge about human osteogenesis by investigating the protein expression during the time-course of glucocorticoid-induced osteoblast differentiation and mineralization (differentiating osteoblasts). For this purpose, we used the well-characterized preosteoblast cell line SV-HFO ${ }^{15}$ that develops into mature osteoblasts in a 3-week time period in the presence of glucocorticoids. ${ }^{5}$ Two mass spectrometry platforms were used for purposes of 
identification (nano-LC-MS/MS using an LTQ-Orbitrap) and quantification (MALDI-FT-ICR-MS). Using nano-LC-MS/MS, we focused on the identification of proteins expressed by differentiating osteoblasts. Moreover, quantitative peptide data was obtained by MALDI-FT-ICR-MS and complemented with specific data-dependent peptide/protein identification by nanoLC-MS/MS. ${ }^{16}$

\section{Materials and Methods}

Cell Culture. Human SV-HFO cells were seeded in a density of $5 \times 10^{3}$ vital cells $/ \mathrm{cm}^{2}$ and precultured for 1 week in $\alpha$-MEM (GIBCO, Paisley, U.K.) supplemented with $20 \mathrm{mM}$ HEPES, $\mathrm{pH}$ 7.5 (Sigma, St. Louis, MO), streptomycin/penicillin, $1.8 \mathrm{mM}$ $\mathrm{CaCl}_{2}$ (Sigma), and $10 \%$ heat-inactivated FCS (GIBCO) at $37{ }^{\circ} \mathrm{C}$ and $5 \% \mathrm{CO}_{2}$ in a humidified atmosphere. During preculture, cells remained in an undifferentiated stage. At this point, cells were seeded in a density of $1 \times 10^{4}$ vital cells $/ \mathrm{cm}^{2}$ in the presence of $2 \%$ charcoal-treated FCS. For induction of osteoblast differentiation and mineralization, the basal medium was freshly supplemented with $10 \mathrm{mM} \beta$-glycerophosphate (Sigma) and $100 \mathrm{nM}$ dexamethasone (Sigma). For the nondifferentiating osteoblasts, the culture condition was identical except for the presence of dexamethasone. Throughout the remainder of the study, DEX-treated and non-DEX-treated cultures are referred as differentiating and nondifferentiating osteoblasts, respectively. The media was replaced every $2-3$ days in both nondifferentiating and differentiating osteoblasts.

Alkaline Phosphatase. ALP activity was assayed by determining the release of paranitrophenol from paranitrophenylphosphate $(20 \mathrm{mM}$ diethanolamine buffer supplemented with $1 \mathrm{mM} \mathrm{MgCl}_{2}$ at $\mathrm{pH}$ 9.8) in the SV-HFO lysates for $10 \mathrm{~min}$ at $37^{\circ} \mathrm{C}$. Adding $0.06 \mathrm{M} \mathrm{NaOH}$ stopped the reaction. Adsorption was measured at $405 \mathrm{~nm}$. Results were corrected for the DNA content of the cell lysates.

Mineralization. For quantification of the mineral content, cell lysates were incubated overnight in $0.24 \mathrm{M} \mathrm{HCl}$ at $4{ }^{\circ} \mathrm{C}$. Calcium content was colorimetrically determined with a calcium assay kit (Sigma) according to the manufacturer's instructions. Results were corrected for the DNA content of the cell lysates. For Alizarin Red staining, cell cultures were fixed for $60 \mathrm{~min}$ with $70 \%$ ethanol on ice. After fixation, cells were washed twice with PBS and stained for 10 min with Alizarin Red solution (saturated Alizarin Red in demineralized water was titrated to $\mathrm{pH} 4.2$ using $0.5 \%$ ammonium hydroxide).

Protein Isolation. At day 5, 10, and 19 of culture, nondifferentiating and differentiating cells, in three biological replicates (a total of 18 samples), were washed in phosphatebuffered saline (PBS, GIBCO) and lysed directly in a culture dish by adding TRIzol (Invitrogen, Carlsbad, CA). The protein phenol-ethanol phase was stored at $-80{ }^{\circ} \mathrm{C}$. Proteins were precipitated using methanol/chloroform. ${ }^{17}$ To facilitate protein solubilization and enzymatic cleavage of proteins, pellets were resuspended in $100 \mu \mathrm{L}$ of $0.1 \%$ (w/v) RapiGest SF (Waters, Milford, MA) in $50 \mathrm{mM}$ ammonium bicarbonate and dissolved by sonification at $70 \%$ amplitude and maximum temperature of $18{ }^{\circ} \mathrm{C}$ (Bransons Ultrasonics, Danbury, CT) until no aggregates were visible. Protein concentration was determined using a BCA kit (Pierce Biotechnology, Rockford, IL). For digestion, $0.1 \mathrm{mg} / \mathrm{mL}$ of trypsin gold, MS grade (Promega, Madison, WI) reconstituted in $50 \mathrm{mM}$ acetic acid was added to each sample, at a 1:50 (w/w) ratio. After overnight incubation at $37^{\circ} \mathrm{C}, 10 \%$ trifluoracetic acid (TFA) was added to the digested protein samples in order to stop the enzymatic reaction and remove Rapigest hydrolytic byproduct (final TFA concentration $0.5 \%, \mathrm{pH}<2$ ). Finally, samples were aliquoted and stored at $-80{ }^{\circ} \mathrm{C}$ until use for LC-MS/MS and MALDI-FT-ICR-MS.

LC-MS/MS. One microliter of protein sample was injected onto a nanoLC system (Dionex, Amsterdam, The Netherlands) and trapped for $7.5 \mathrm{~min}$ on a C18 PepMap 100 column (5 mm $\times 300 \mu \mathrm{m}$ i.d., Dionex, Sunnyvale, CA). Fractionation was performed using a C18 PepMap 100 column $(150 \mathrm{~mm} \times 75 \mu \mathrm{m}$, $3 \mu \mathrm{m}, 100 \AA$, Dionex, Sunnyvale, CA) using a 80 min gradient running from $0-50 \%$ of buffer A ( $80 \%$ acetonitrile (ACN), $20 \%$ $\mathrm{H}_{2} \mathrm{O}, 0.1 \%$ TFA) in buffer $\mathrm{B}\left(100 \% \mathrm{H}_{2} \mathrm{O}, 0.1 \%\right.$ TFA), followed by a $23.5 \mathrm{~min}$ gradient to $100 \% \mathrm{~B}$ at $250 \mathrm{~nL} / \mathrm{min}$ (Dionex). A UV detector $(214 \mathrm{~nm})$ was used to monitor the separation. The nanoLC was coupled to a LTQ-Orbitrap (Thermo Fisher Scientific, Bremen, Germany). Mass spectrometry data was acquired in both data-independent and dependent mode, the latter to include those peptide masses found to be differentially expressed by MALDI-FT-ICR-MS measurements (see below) for specific sequencing. This preselection of data results in an increased chance to identify the peptides of interest than just by default data independent measurements. The mass tolerance of the selected inclusion list was $10 \mathrm{ppm}$.

Fragmentation spectra were searched against the Human International Protein Index (IPI) database v3.18 (June 13, 2006) with SEQUEST using the Bioworks software (Version 3.3, Thermo Electron, San Jose, CA). The mass accuracy for the database was set to $5 \mathrm{ppm}$ for the precursor ions and $1 \mathrm{Da}$ for the fragment ions. Only peptides with a probability less than 0.001 and meeting the SEQUEST HUPO PPP high confidence parameters $^{18,19}$ were considered for further analysis.

Peptides masses within a mass window of $7 \mathrm{ppm}$ to LC-MS/ MS and 2 ppm to the FT-ICR-MS (see section below) measurements were considered as identified. To verify isoform specificity and eliminate redundant protein identifications, the peptides were searched against the same IPI Human database using Standalone Blast (Basic Local Alignment Search Tool) software version 2.2.17 with the PAM30 scoring matrix for short amino acid sequences. Sequence coverage determination was performed using the Protein Coverage Summarizer v1.2.3064 tool, freely available in the PNNL/OMICS.PNNL.GOV Web site (http://omics.pnl.gov/software/ProteinCoverageSummarizer. php).

Bioinformatic Gene Ontology Analysis. Proteins identified in the normal scan mode by LC-MS/MS were analyzed using Ingenuity Pathway Analysis (version 7.60) and DAVID BioinformaticsResourcesv6.7 (http://david.abcc.ncifcrf.gov/home.jsp) ${ }^{20,21}$ to obtain a comprehensive description of the overrepresented biological processes and functional related groups of proteins within our data set. For DAVID analysis, only Bonferroni significant ( $p$-value $<0.001$ ) overrepresented terms, containing more than 9 proteins, were considered. As background, the default Homo sapiens genome was used.

MALDI-FT-ICR-MS. Half microliter of protein sample was mixed with a 2,5-dihydroxy benzoic acid (DHB, Bruker Daltonics, Bremen, Germany) matrix solution ( $10 \mathrm{mg} / \mathrm{mL}$ in $0.1 \%$ TFA/water) in a 1:1 (v/v) ratio, spotted onto a 600/384 AnchorChip target plate (Bruker Daltonics) in duplicate, and allowed to dry at room temperature. MALDI-FTICR MS measurements were performed in a Bruker Apex-Q equipped with a $9.4 \mathrm{~T}$ magnet (Bruker Daltonics). For each measurement, scans of 10 shots at $75 \%$ laser power were accumulated. Mass spectra were acquired in the mass range of 800-4000 Da and processed with a Gaussian filter and 2 zero fillings. To ensure good mass 
accuracy, an external calibration was performed using a Peptide Calibration Standard II (Bruker Daltonics), a mixture that contains Bradykin 1-7, Angiotensin II, Angiotensin I, Substance P, Bombesin, Renin Substrate, ACTH clip 1-17, ACTH clip 18-39, and Somatostatin 28. The 18 samples were measured randomly in triplicate and a total of 54 individual spectra were acquired.

Internal Calibration of FT-ICR-MS Data. Raw files obtained from the FT-ICR-MS were used as input for homemade software described elsewhere. ${ }^{22-24}$ Spectra were internally calibrated using 5 omnipresent Actin peptide masses dispersed within the measurement range: 1198.7054, 1515.7491, 1790.8919, 1954.0643, and 2215.0699. After internal calibration, the accuracy of the measurements was assessed using 7 peptide masses derived from tubulin, GAPDH and HSPA5: 1143.6351, 1566.7795, 1613.9024, 1701.9072, 1701.9072, 1756.9660, 1824.9863, and 2007.8933. On the basis of these peptides, an average accuracy of less than $1 \mathrm{ppm}$ was obtained. The final matrix contained all masses detected and their respective intensities, in at least 3 independent measurements and with a signal-tonoise $(\mathrm{S} / \mathrm{N})>4$ to avoid noise peaks.

Normalization of FT-ICR-MS Data. Normalization of the measured intensities was achieved multiplying them by a normalization factor. This factor was determined by the ratio of average intensity of all samples to average intensity of the sample to be normalized. After normalization, we inspected the reproducibility for both technical and biological replicates by calculating the coefficient of variance of the 63 peptide masses detected in all samples. For technical replicates, the average CV was $11 \%$ (range $7-15 \%$ ), and, for biological replicates, the CV was $26 \%$ (range $19-36 \%$ ).

Selection of Differentially Expressed Peptides. Comparison of normalized peptide intensities, including zero values, was performed using a Wilcoxon test. ${ }^{24}$ In a first set of analysis, peptide intensities at a specific culture time point (day 5, day 10 , or day 19) were compared between nondifferentiating and differentiating samples. In a second set of analysis, peptide intensities were compared as a function of time during culture for both nondifferentiating and differentiating conditions. Peptide masses with a $p$-value $<0.001$ and a $p$-value $<0.01$ showing an absolute difference (present and absent) between the compared conditions were identified as being differently expressed.

Data Visualization. The geometrical mean of the normalized intensities of all samples was calculated. Values of intensity equal to 0 were regarded as Not a Number (NaN). The level of expression of each peptide mass in every sample was determined relative to this geometric mean and logarithmically transformed (on a base 2 scale). Deviation from the geometrical mean was considered as differential expression, despite possible unaccountable bias introduced by the MALDI ionization process and the analyte interaction with the matrix used. To minimize the latter possibility, we have measured all samples in triplicate, observing acceptable CVs $(7-15 \%)$ in contrast to other equipments, like the MALDI-TOF, where CVs can be as high as $30 \%$. Similarity between samples, plotted by Pearson's correlation, was done using Omniviz (OmniViz, Maynard, MA, version 5.0).

Immunodetection. Cell culture and protein isolation for Western blotting experiments were identical to those described above. Equal amounts of protein per sample were loaded and separated by SDS-PAGE (10\% Ready Gel Precast Gels, Bio-Rad, Hercules, CA) and transferred onto a nitrocellulose membrane
(Hybond-ECL, Amersham Biosciences, Buckinghamshire, U.K.). After blocking nonspecific signal with $4 \%$ fat free milk in Trisbuffered saline (TBS), the membrane was incubated with specific antibodies against fibronectin (mouse monoclonal to FN1; 1:5000, Ab-11, Clone FBN11, NeoMarkers, Cat. MS-1351), annexin A2 (rabbit polyclonal to ANXA2; $1 \mu \mathrm{g} / \mathrm{mL}$, Abcam, Cat. Ab41803), and GAPDH (loading control; mouse monoclonal; 1:20 000, Millipore, Cat. MAB374). Membranes were probed with secondary antibodies, goat anti-mouse or goat anti-rabbit IgG, conjugated with Alexa Fluor 680 (1:5000, Invitrogen, Cat. A21057) or with IRDye 800CW (1:5000, LI-COR, Cat. 926-32211), respectively. Immunoreactive bands were visualized using the LI-COR Infrared Imaging System according to the manufacturer's instructions (Odyssey Lincoln, NE).

FN1 expression was visualized by immunocytochemistry. Nondifferentiating and differentiating cells were cultured in similar conditions used for the MS analysis. After fixation in $10 \%$ formalin and blocking in PBS $/ 2 \%$ BSA, cells were incubated with mouse monoclonal FN1 antibody (1:100, Ab-11, Clone FBN11, NeoMarkers, Cat. MS-1351). Next, slides were incubated with secondary antibody, goat anti-mouse IgG conjugated with Alexa Fluor 680 (1:300, Invitrogen, Cat. A21057). Slides were washed 3 times in PBS $/ 0.2 \%$ BSA, one time in PBS, one time in $70 \%$ ethanol, and finally in $100 \%$ ethanol. After washing, they were mounted in VectaShield containing DAPI (Vector Laboratories, Burlingame, CA). As negative control, cells were not incubated with primary antibody.

\section{Results}

ALP Activity and Mineralization of Human Preosteoblasts. In this study, human preosteoblasts (SV-HFO) were used, which can be stimulated to differentiate into mature osteoblasts that produce a collagenous ECM that subsequently accumulates mineral. Measuring parameters such as ALP activity and calcium deposition over time can monitor this process. As shown in Figure 1A, differentiating osteoblasts exhibited an increase in ALP activity with a peak around day 10. The ALP increase was followed by a rapid deposition of calcium (Figure 1B). This in vitro bone formation model is an excellent model to study protein expression within the different stages of osteoblast differentiation.

Qualitative LC-MS/MS Proteome Analysis: Proteins Identified in Differentiating Human Osteoblast Cultures. To identify as many as possible proteins, we combined chromatographic techniques upstream to detailed MS measurements (nano-LC-MS/MS). We have used the capabilities of this technique to get qualitative insights into the proteins expressed by differentiating osteoblasts combining data from days 5,10 , and 19. This resulted in the successful identification of 381 proteins (Supplementary Table 1). To categorize the identified osteoblast proteins, we performed gene ontology (GO) annotation overrepresentation analyses. The proteins were categorized for their annotation related to Biological Process (BP), Molecular Function (MF), and Cellular Compartment (CC). Figure 2A depicts the significant top GO term categorization by overrepresentation. Several overrepresented terms were related to cytoskeleton such as structural constituent of the cytoskeleton (GO:0005200), actin cytoskeleton (GO:00015629), and actin filament-based process (GO:0030029). Pyrophosphatase activity (GO:0016462) proteins were overrepresented, as well as proteins involved in other distinct processes like energy metabolism (GO:0006096) or antigen processing and presentation (GO: 0042612; GO:0002474). In addition, the proteins were also 
A

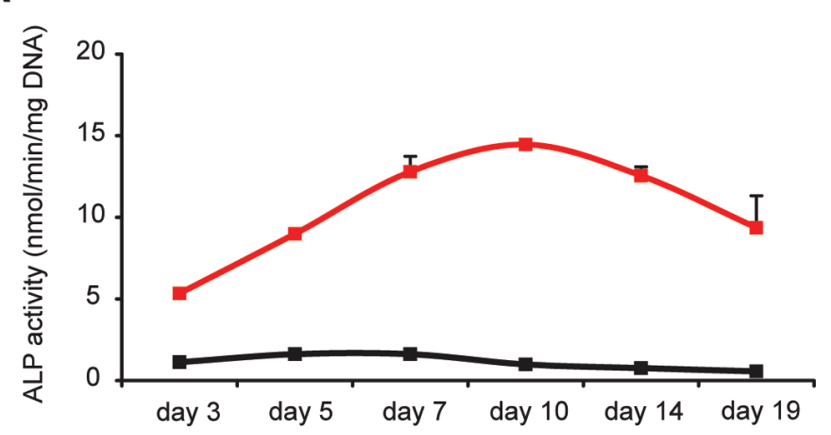

B

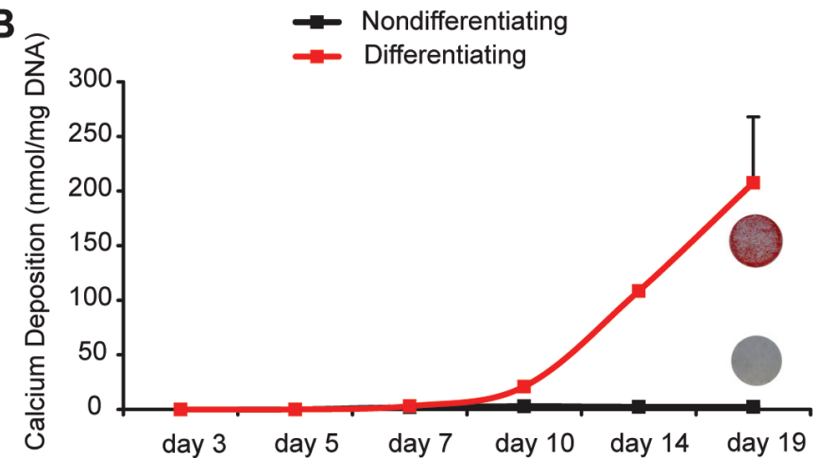

Figure 1. (A) Alkaline phosphatase activity and (B) calcium deposition in the matrix corrected for cell number (as determined by DNA measurement) in nondifferentiating and differentiating human osteoblast cultures. Insets with Alizarin Red staining at the final time point (day 19) are also shown.

categorized in protein families (Figure 2B). Enzymes were the second biggest group of proteins (85 proteins) followed by transporters (18). Phosphatases and ion channels (5 proteins each) were also detected and represent an interesting group of proteins for the process under study, where phosphate and calcium ions represent the foundations for ECM mineralization.

We further inspected for proteins identified and GO annotations that are established players in osteoblast differentiation (Table 1). We have identified 5 proteins linked to skeletal system development, several ECM components including collagens and collagen binding proteins, and proteins that bind to integrins, which are important for ECM-cell signal transduction and osteoblast function (reviewed by Damsky et al., 1999). Other osteoblast-relevant categories included proteins possessing pyrophosphatase activity and calcium ion binding proteins with 41 and 29 proteins, respectively.

Quantitative MALDI-FT-ICR-MS Proteome Analysis: Differentially Expressed Proteins in Mineralization Period. Following the qualitative analysis, we used MALDI-FT-ICR-MS to gather quantitative protein expression profiles. A total of 54 individual spectra were obtained corresponding to the day 5 , 10 , and 19 of differentiating and nondifferentiating conditions, analyzed in 3 biological and 3 technical replicates. Data was used as input for homemade software ${ }^{24}$ in order to generate a data file containing all information regarding to peptide masses detected and their respective intensities. For each spectrum, we obtained 1688-2204 monoisotopic masses. The exception was one spectrum, a technical replicate of a sample from day 10 nondifferentiating condition, that showed only 814 masses and which was excluded from further analysis. Upon performing internal calibration, we obtained an average accuracy below
1 ppm in agreement with previous reports using similar equipment. $^{26,27}$ We compared all samples according to the criteria mentioned in the Material and Methods (Selection of Differentially Expressed Peptides) and identified 422 peptide masses as significantly differentially expressed. Correlation analysis based on measured intensities of these 422 peptide masses is shown in Figure 3. It is interesting that this unbiased approach delivered a correlation plot with a divergence of the differentiating and nondifferentiating conditions. Within the differentiating condition, there was also a clear discrepancy between the premineralization and mineralization periods, with a very strong correlation between the samples of the mineralization period (Figure 3). In addition, technical and biological replicates always clustered together demonstrating the robustness of the MALDI-FT-ICR-MS measurements.

These observations prompted us to examine in more detail the protein expression differences within the differentiating condition, comparing mineralization (day 19) versus the preceding premineralization period (days 5 and 10). Additionally, we included in these analyses the two extreme phenotypes, that is, day 19 in differentiating and nondifferentiating condition. In total, these comparisons led to an identification of 52 differently expressed proteins (Table 2), according to the criteria to combine MALDI-FT-ICR-MS and LC-MS/MS data mentioned in the Materials and Methods. Among other proteins, cytoskeleton (actins, tubulins, and vimentin), actin binding (CCT2, CSRP1, FLNA, MYH9, and VCL), ECM (FN1, LGALS1), and calcium binding proteins (ANXA2, ANXA1) were identified.

Validation of Protein Expression and MS-Based Quantification. We verified that most of the (FT-ICR-MS) quantified peptides, mapping to the same protein, have similar expression patterns (Figure 4A). To validate the MS data, we selected two differentially expressed proteins that have been reported to be relevant for bone biology, ANXA2 and FN1. The expression pattern of these proteins was similar for both FTICR-MS and Western blotting (Figure 4A,B). We have also performed immunocytochemistry for FN1. As expected, FN1 immunocytochemistry from mineralized day 19 osteoblasts disclosed a clear extracellular localization of this protein (Figure 4C).

\section{Discussion}

In vitro Human osteoblast differentiation models can be an effective model to detect proteins that have pivotal roles in bone formation and potential targets to shift bone remodeling toward the anabolic process. The introduction of mass spectrometry into the proteomics field has made this type of analysis feasible, revealing large set of proteins that can be analyzed using bioinformatics tools to discover protein associations or overrepresented biological processes.

In the present work, we aimed to identify and quantify proteins in an effort to gain knowledge about the osteoblast differentiation process and identify novel proteins that may modulate osteoblast mineralization. To this end, we exploited our very well characterized human preosteoblast cell model ${ }^{5,15}$ and mass spectrometric analyses to identify proteins against the background of osteoblast differentiation and in vitro bone formation. Furthermore, we aimed to assess quantitative differences both between differentiated mineralized cultures and their nondifferentiated counterparts, as well as between the premineralization and mineralization periods of the differentiated osteoblast culture. 
A

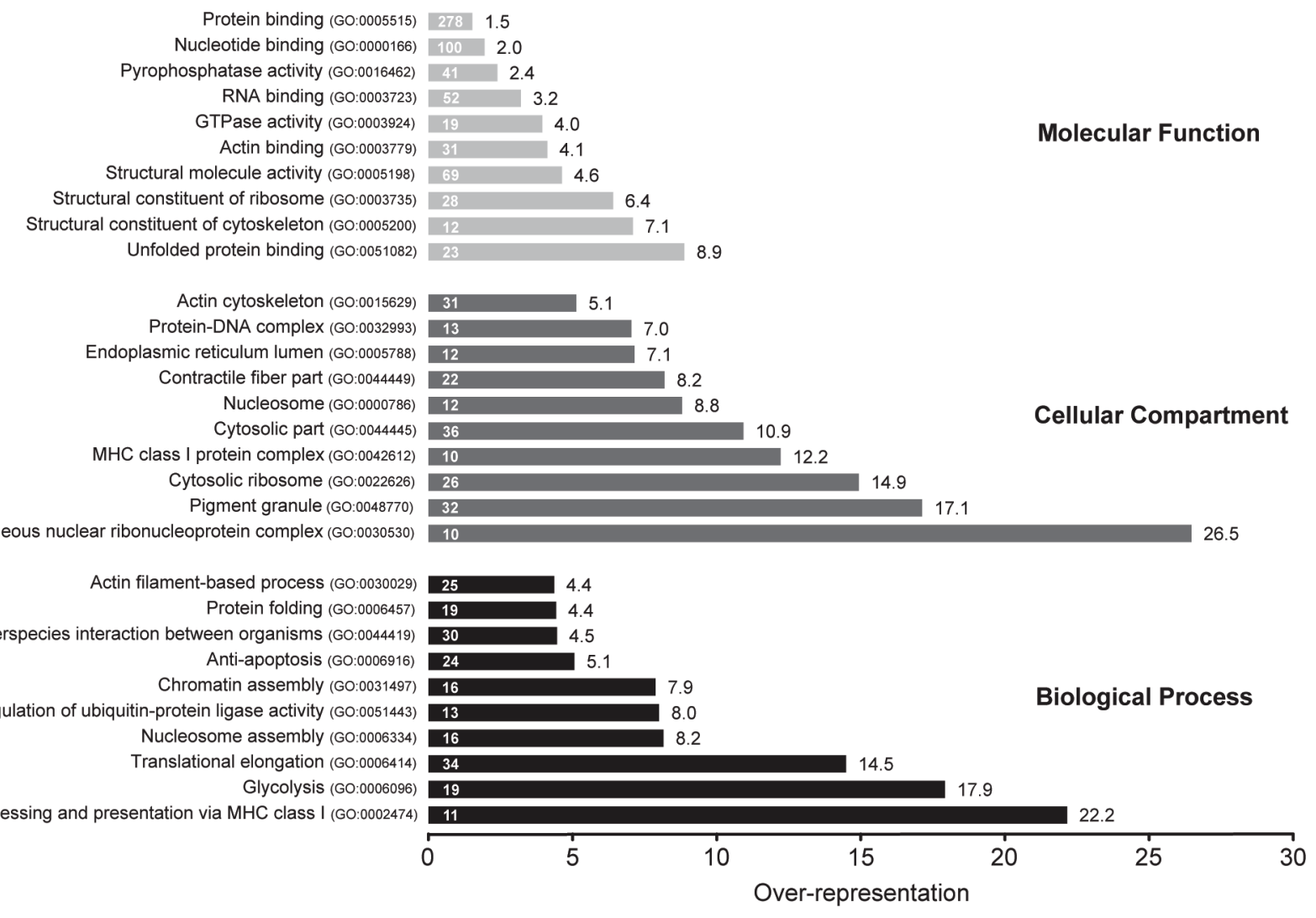

B

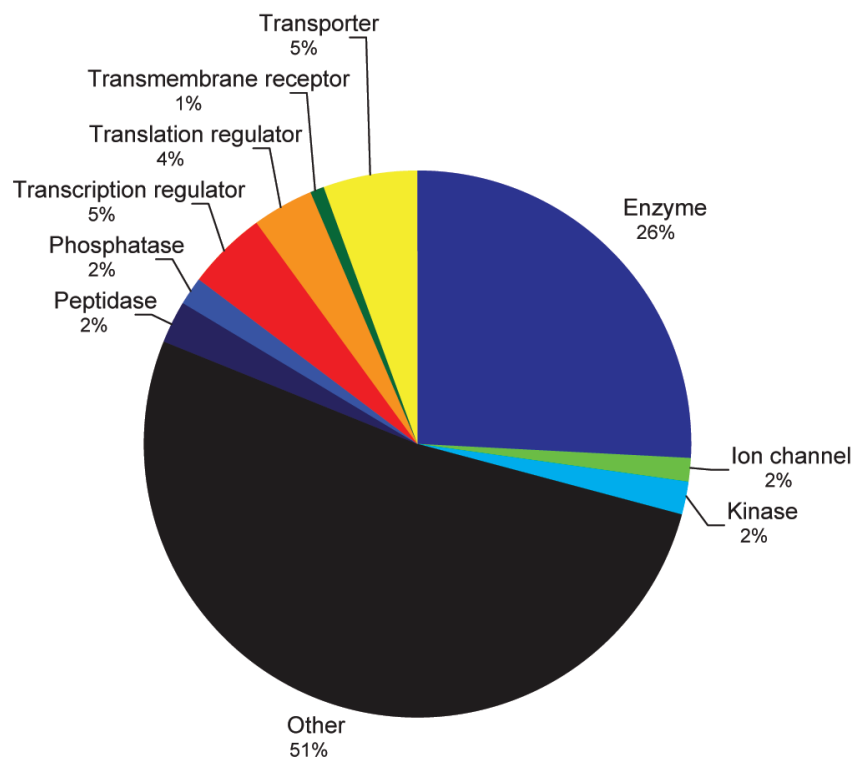

Figure 2. (A) Gene Ontology of the significantly overrepresented terms in differentiating osteoblasts (Bonferroni $p$-value $<0.001$ ). Only the 10 highest overrepresented terms for biological process, molecular function and cellular compartment categories are shown. Numbers next to the bars indicate overrepresentation level and numbers embedded in the bars indicate the proteins identified by MS/MS for each category. (B) Pie chart representing the functional group distribution of the 381 identified proteins in differentiating osteoblast cultures.

With regard to the protein profile of differentiating osteoblasts, we have identified 381 proteins. GO analysis revealed that cytoskeleton and cytoskeletal related processes were among the highest overrepresented terms. This shows the importance of specific cytoskeleton assembly for osteoblast differentiation, also verified by Higuchi and co-workers. ${ }^{28}$ It is known that actin filaments (stress fibers) are physically linked to the ECM by integrins. ${ }^{28-30}$ These transmembrane glycopro- teins can interact with ECM proteins bridging the extracellular with the intracellular compartment. This interaction affects the organization of the cytoskeleton, ${ }^{31}$ signal transduction, and the expression of transcription factors and osteoblast-specific genes in osteoblasts. ${ }^{32,33}$ Other identified processes include distinct processes such as glucose metabolism and antigen presentation. New insights linking bone remodeling to energy metabolism control are described in the review by Rosen et al. ${ }^{34}$ The 
Table 1. Gene Ontology Terms Reporting Processes/Functions/Locations Connoted with Osteoblast Function

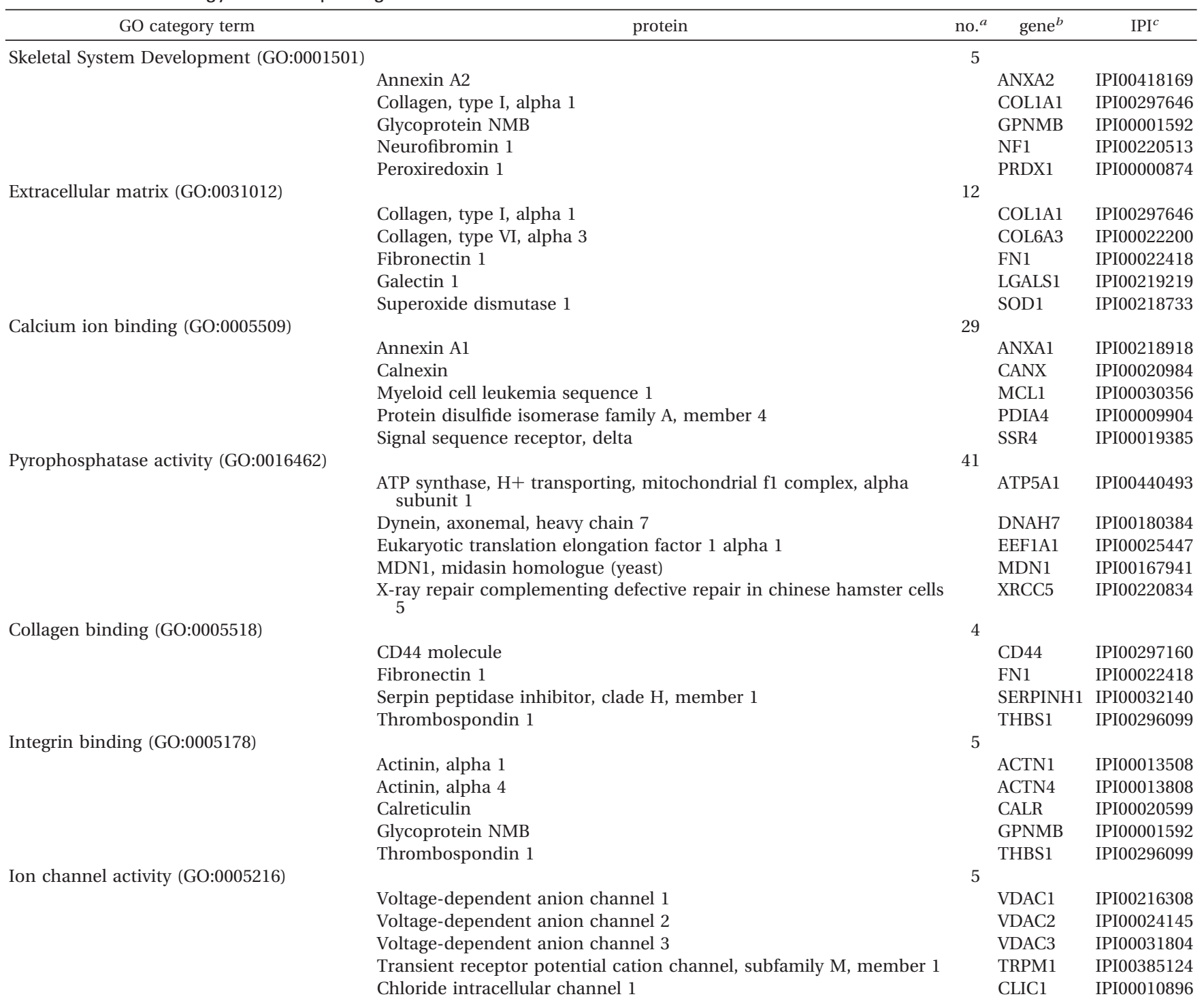

${ }^{a}$ Number of total proteins in the group. ${ }^{b}$ Official gene symbol. ${ }^{c}$ IPI accession number.

fact that these processes were overrepresented can be related to the fact that ECM synthesis, maturation, and mineralization are highly demanding processes, ${ }^{35}$ leading to mitochondrial and antioxidant enzyme changes. ${ }^{36}$

Interestingly, our data show a high overrepresentation of proteins belonging to the MHC class I protein complex involved in antigen presentation. Already back in 1989, Skjødt and coworkers ${ }^{37}$ reported that osteoblast-like cells function as antigen presenting cells, being able to stimulate peripheral bone marrow cells (PBMCs). Since osteoclasts are derived from PBMCs, it is tempting to speculate that overrepresentation of this type of proteins may be related to the osteoblast effectiveness to stimulate osteoclast differentiation from their precursors or to interact with hematopoietic stem cells in the stem cell niche. ${ }^{38}$

Phosphatases and ion channels constitute another group of proteins identified. Some of these proteins have been identified already as important players during osteoblast differentiation. This is the case for the nuclear transmembrane ion channel protein, chloride intracellular channel 1 (CLIC1). Knockdown of CLIC1 suppresses osteoblast dif- ferentiation from MSCs, whereas protein overexpression increases osteogenic markers such as ALP activity. ${ }^{39}$ Other interesting proteins include the voltage-dependent anion channel 1, 2, and 3 (VDAC1, VDAC2, and VDAC3). These membrane proteins play a role in the efflux of metabolites including ATP and phosphate in the mitochondria. ${ }^{40}$ Interestingly, these proteins are recurrently identified in matrix vesicles (MV), ${ }^{14,41}$ the organelles implicated in initiation of mineralization. ${ }^{41,43}$ Start of mineral deposition occurs by accommodating the proper environment for crystal growth in the MV. This implicates mobilization of calcium and phosphate to form hydroxyapatite. Phosphate mobilization can be achieved by degradation of pyrophosphate (PPi), a mineralization inhibitor, into free phosphate (Pi). Our data show that enzymes involved in this process were overrepresented by more than 2-fold (GO:0016462 pyrophosphatase activity, Figure 2A) supporting its importance for osteoblast-mediated ECM mineralization.

In our quantitative MALDI-FT-ICR-MS approach, we identified 52 differentially expressed proteins between day 19 mineralized and day 19 nonmineralized osteoblasts and 
Nondifferentiating

Differentiating

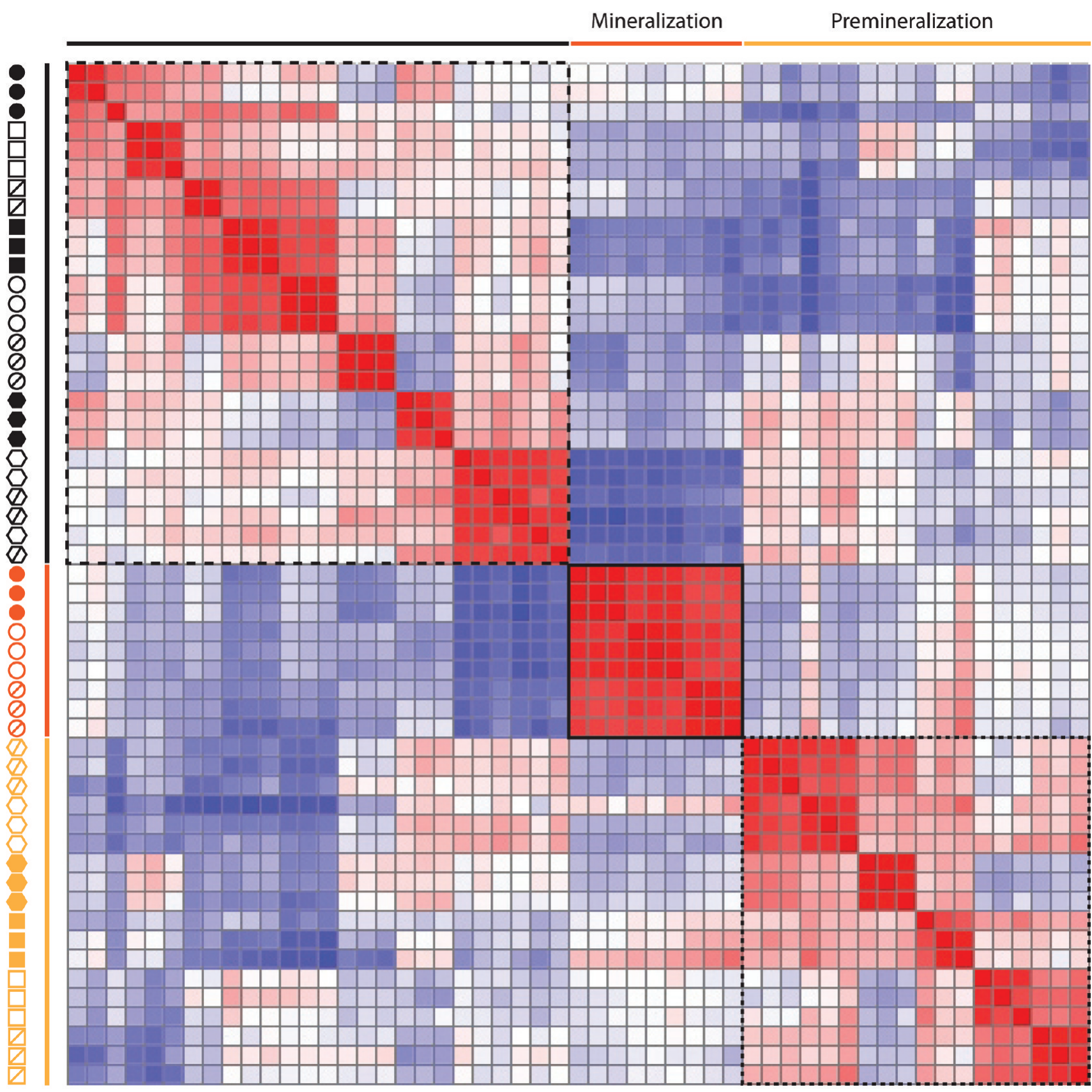

High

Low

Figure 3. Pearson correlation plot of the 422 significant differentially expressed peptide masses as determined by FT-ICR-MS measurements. All samples, from both differentiating and nondifferentiating osteoblasts, are plotted against each other to determine their degree of similarity based on the determined quantitative peptide profile. Lines and geometric shapes: black, nondifferentiating condition; yellow and orange, differentiating condition, premineralization and mineralization period, respectively. Geometric shapes: circles, day 19; squares, day 10; pentagons, day 5; filled, empty and striped shapes represent the 3 biological replicates, measured each in 3 technical replicates (with exception to a technical replicate from day 10 nondifferentiating condition that was excluded from the analysis); Red, high similarity; blue, low similarity.

between day 19 mineralized and the osteoblast premineralization time points, day 5 and day 10. Some of these proteins will be discussed in more detail. We found that cytoskeleton components (several actins, tubulins, and vimentin) and actin binding proteins (CCT2, CSRP1, FLNA, MYH9, and VCL) were differentially expressed in differentiat- ing osteoblasts. This follows the data discussed above and further substantiates a prominent role for cytoskeletal reorganization in osteoblast differentiation. ECM (FN1, LGALS1) and calcium binding (ANXA2, ANXA1) proteins were also identified among differentially expressed proteins. FN1 is an abundant ECM glycoprotein with significantly higher 







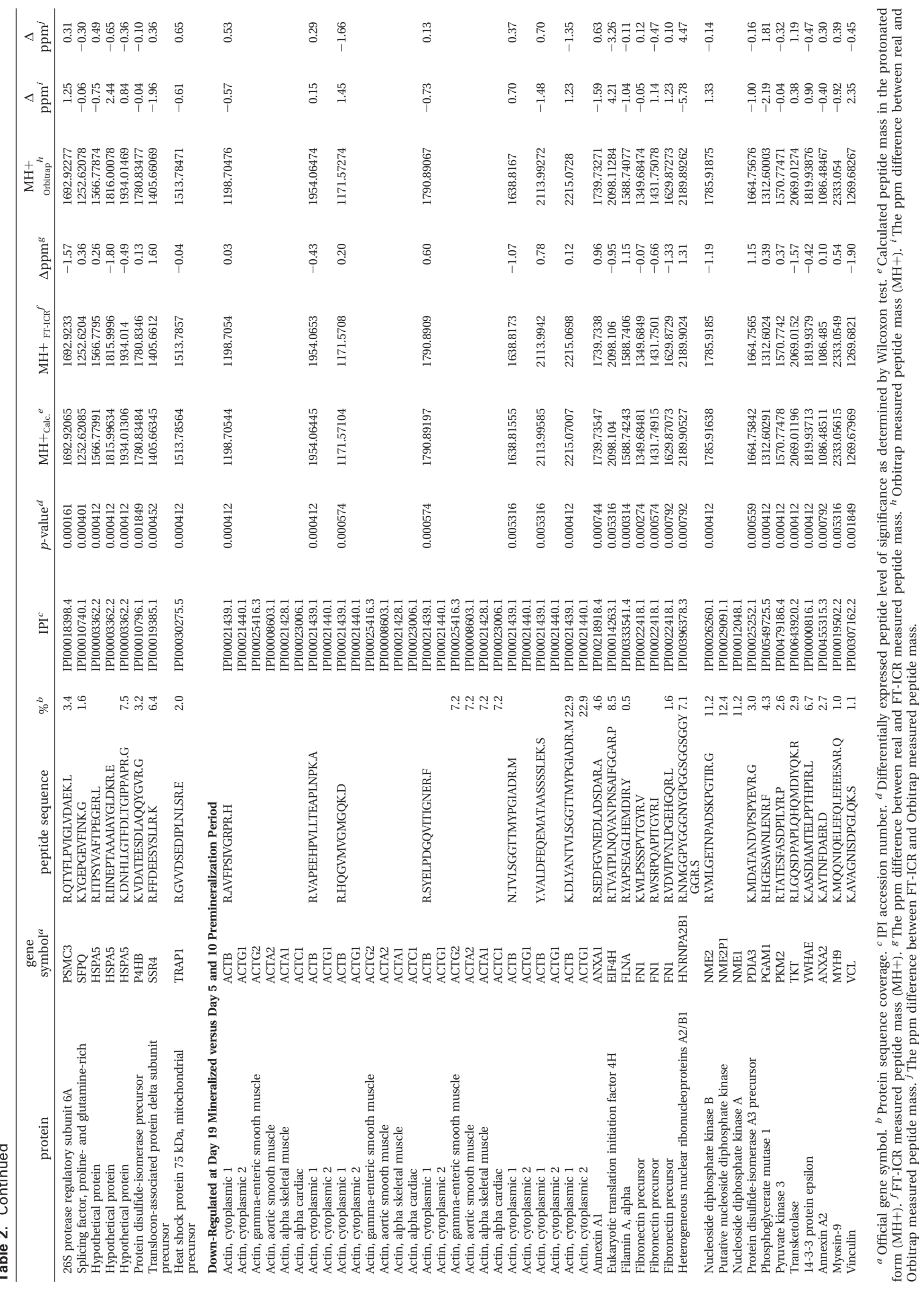



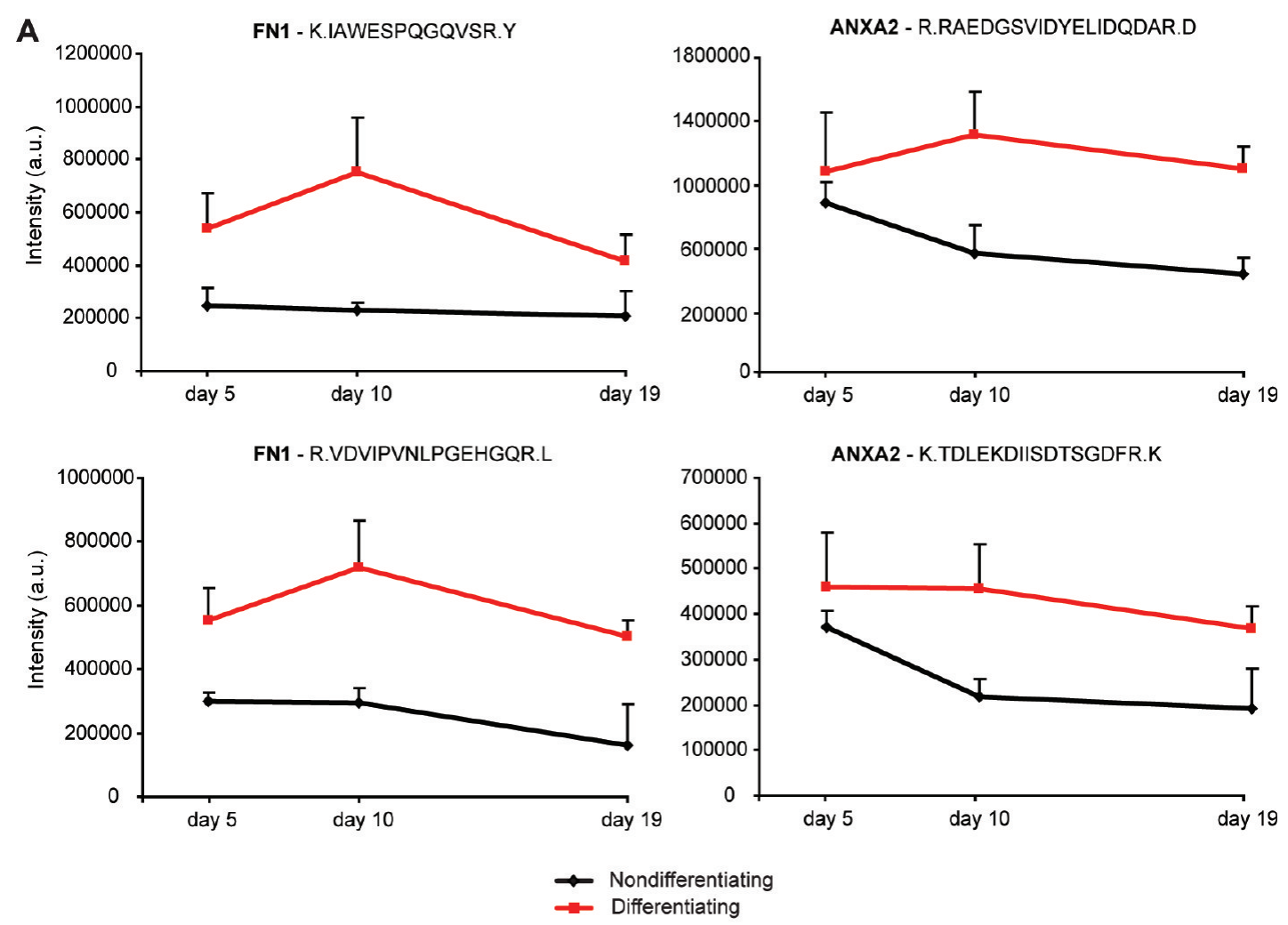

$\mathbf{B}$
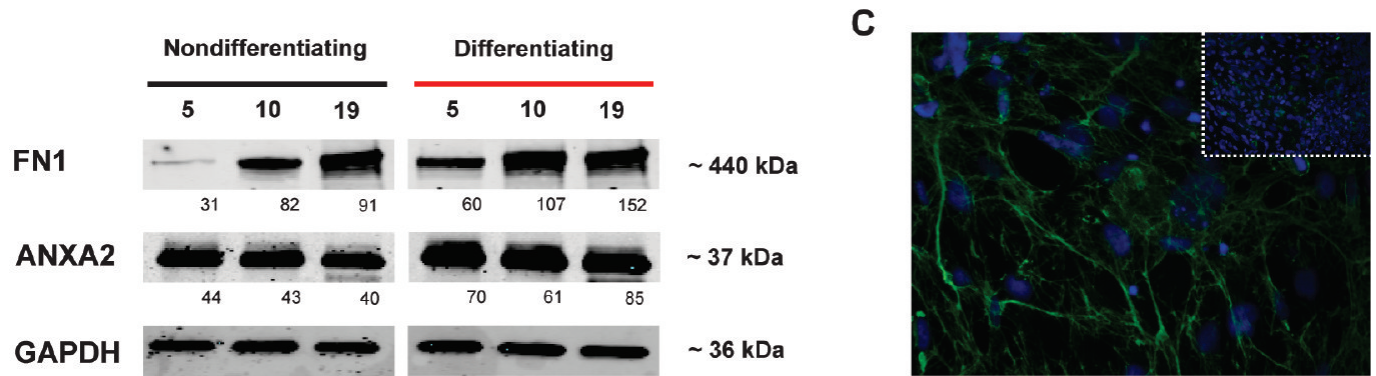

Figure 4. (A) Quantitative FT-ICR-MS profile obtained for FN1 and ANXA2. Two peptides belonging to each of these proteins are shown. (B) Immunodetection of FN1, ANXA2, and GAPDH (loading control). Fluorescence detection was done using the LI-COR system. Numbers were calculated using the band intensities and indicate protein expression relative to GAPDH. (C) Immunocytochemistry for FN1 in SV-HFO cells from day 19 mineralizing condition. Negative control shown as inset.

expression, at all time points analyzed, in differentiating osteoblasts relative to their nondifferentiated counterparts (Figure 4A,B). FN1 is required for osteoblast differentiation and mineralization through interaction with the integrin $\alpha 5 \beta 1$ FN1 receptor. ${ }^{44}$ Besides determining osteoblast cellular fate, $\mathrm{FN} 1$ is also required for their survival once osteoblasts are mature. ${ }^{45}$ We identified ANXA2 as a protein that was enhanced during stages of premineralization. Other studies showed that osteoblasts overexpressing ANXA2 show enhanced mineralization. ${ }^{46}$ ANXA2 is a calcium-dependent phospholipid binding protein located in the ECM and in $\mathrm{MV}^{14,43}$ where they are thought to be important for $\mathrm{Ca}^{2+}$ uptake. ${ }^{47}$ The fact that we observed the highest expression of ANXA2 in the premineralization phase might be associated with increasing ALP activity verified at this stage and the start of $\mathrm{Ca}^{2+}$ uptake into the MV. Interestingly, ANXA2 has been shown to be an autocrine factor for osteoclasts, increasing osteoclastogenesis and resorption. ${ }^{48,49}$ Here we show that ANXA2 was also expressed and regulated during osteoblast differentiation making it tempting to speculate about implications in the osteoblast-osteoclast crosstalk.

LMNA belongs to the nuclear inner membrane class of proteins. Mutations in this gene display a phenotype compatible with progeria syndrome exhibiting loss of subcutaneous fat, muscular dystrophy, and an osteoporotic phenotype. ${ }^{22}$ The bone phenotype is thought to be due to a deficit in osteoblast and matrix formation. ${ }^{50,51}$ Our data supports the importance of this protein for osteoblast differentiation, with higher expression in differentiating cells. However, while ANXA2 and FN1 levels were higher prior to mineralization, LMNA expression peaked when cells were mature. This difference in expression pattern is probably related to the physiological changes of the osteoblast in its progression toward osteocyte. Thus, these proteins seem to represent hallmarks of the period of osteoblast development, ANXA2 and FN1 of the premineralization, and LMNA of the mineralization period.

Also proteins were specifically suppressed in late staged differentiating osteoblasts, including PLOD2, NTE5, and 
LGALS1. PLOD2 forms hydroxylysine residues in -Xaa-LysGly- sequences in collagens that serve as sites of attachment for carbohydrate units being essential for the stability of the intermolecular collagen cross-links. Mutations in PLOD2 cause Bruck Syndrome in which the bone collagen lacks pyridinolines and the other cross-links based on hydroxylysine aldehydes. ${ }^{52}$ NTE5, more often referred to as CD73, is a glycosyl phosphatidylinositol (GPI) plasma membrane anchored enzyme, ${ }^{53}$ regarded as a MSC marker. ${ }^{54,55}$ LGALS1 is a $\beta$-galactoside-binding protein that has been implicated in several processes from cell adhesion and migration ${ }^{56}$ to proliferation $^{57}$ and apoptosis. ${ }^{58}$ Human fetal MSCs upon exposure to LGALS1 enter myogenic differentiation. ${ }^{59}$ Downregulation of PLOD2 upon mineralization is perhaps an indication that collagen cross-linking regulation is mostly needed in the premineralization stage, when ECM is actively synthesized. NTE5 and LGALS1 decreased expression might be a sign of cellular maturity toward fully differentiated osteoblasts.

Like any other approach, the use of the MALDI-FT-ICRMS for label-free quantitation has its own advantages and disadvantages. Among the latter is the need to use an independent platform to identify the peptides/proteins profiled, due to the inability to generate good fragmentation data on single charged MALDI ions in FTMS by collisioninduced dissociation. ${ }^{60}$ On the other hand, MALDI-FT-ICRMS data does not require extensive data processing and analysis. Other advantages include the high sensitivity and high mass resolution described elsewhere, ${ }^{60-62}$ and the superior reproducibility of these MS measurements, crucial in quantitative proteomics. Variation of peptide intensity measurements was as low as $15 \%$ in technical replicates and $36 \%$ considering biological replicates. For the majority of the different peptides detected that belong to the same protein, the FT-ICR-MS determined expression patterns were similar. Moreover, immunodetection of FN1 and ANXA2 confirmed their up-regulation in differentiated osteoblasts compared to their nondifferentiating counterparts.

From the list of proteins generated, it is evident that classical osteoblast markers such as RUNX2, ALPL, SPP1, BGLAP, and SPARC were not observed. We believe that this was due to the fact that their concentrations were low and beyond the range we could detect. In human cells, the range of protein copy numbers is $7-8$ orders of magnitude, ${ }^{63}$ while MS analysis can only cover up to $4-6 .{ }^{64}$ To tackle this problem, we believe that the approach here described should be combined with the isolation of subcellular and ECM proteomes.

This study aimed to contribute to the knowledge of the osteoblast differentiation program by an unbiased mass spectrometry-based proteomics approach. Qualitative analysis revealed not only proteins expressed by differentiating osteoblasts, but also biological processes and molecular functions that drive cells toward bone formation and mineralization. At this level, cytoskeleton, energy metabolism, and antigen presentation processes were among the most overrepresented categories. Complementation of the analysis with quantitative differences revealed both bone related proteins, with characteristic expression patterns in the course of differentiation (ANXA2, FN1, and LMNA), and other proteins (e.g., LGALS1) not extensively studied in the bone field. The identification of proteins having a proven role in bone function in addition to others with yet unknown bone function strongly supports that the latter are also important for osteoblast differentiation and mineralization. Altogether, our data provides more information in the pursuit of targets for bone formation modulation, which is of utmost importance to develop new therapies for bone related diseases such as osteoporosis.

Acknowledgment. This work was supported by ZonMW TOP grant (contract grant number: 91206069) and the Erasmus Medical Center, Rotterdam, The Netherlands.

Supporting Information Available: Full list of identified proteins: Supplementary Table 1, proteins identified by MS/MS in the distinct samples analyzed from differentiating osteoblast cultures at day 5, 10 and 19. This material is available free of charge via the Internet at http://pubs.acs.org.

\section{References}

(1) Ducy, P.; Zhang, R.; Geoffroy, V.; Ridall, A. L.; Karsenty, G. Osf2/ Cbfa1: A transcriptional activator of osteoblast differentiation. Cell 1997, 89, 747-754.

(2) Komori, T.; Yagi, H.; Nomura, S.; Yamaguchi, A.; Sasaki, K.; Deguchi, K.; Shimizu, Y.; Bronson, R. T.; Gao, Y. H.; Inada, M.; Sato, M.; Okamoto, R.; Kitamura, Y.; Yoshiki, S.; Kishimoto, T. Targeted disruption of Cbfal results in a complete lack of bone formation owing to maturational arrest of osteoblasts. Cell 1997, 89, 755-764.

(3) Otto, F.; Thornell, A. P.; Crompton, T.; Denzel, A.; Gilmour, K. C.; Rosewell, I. R.; Stamp, G. W. H.; Beddington, R. S. P.; Mundlos, S.; Olsen, B. R.; Selby, P. B.; Owen, M. J. Cbfa1, a candidate gene for cleidocranial dysplasia syndrome, is essential for osteoblast differentiation and bone development. Cell 1997, 89, 765-771.

(4) Aubin, J. E. Regulation of osteoblast formation and function. Rev. Endocr. Metab. Disord. 2001, 2, 81-94.

(5) Eijken, M.; Koedam, M.; van Driel, M.; Buurman, C. J.; Pols, H. A.; van Leeuwen, J. P. The essential role of glucocorticoids for proper human osteoblast differentiation and matrix mineralization. Mol. Cell. Endocrinol. 2006, 248, 87-93.

(6) Herbertson, A.; Aubin, J. E. Dexamethasone alters the subpopulation make-up of rat bone marrow stromal cell cultures. J. Bone Miner. Res. 1995, 10, 285-294.

(7) Iba, K.; Chiba, H.; Sawada, N.; Hirota, S.; Ishii, S.; Mori, M. Glucocorticoids induce mineralization coupled with bone protein expression without influence on growth of a human osteoblastic cell line. Cell Struct. Funct. 1995, 20, 319-330.

(8) Patterson, S. D.; Aebersold, R. H. Proteomics: the first decade and beyond. Nat. Genet. 2003, 33, 311-323.

(9) Tyers, M.; Mann, M. From genomics to proteomics. Nature 2003, 422, 193-197.

(10) Foster, L. J.; Zeemann, P. A.; Li, C.; Mann, M.; Jensen, O. N.; Kassem, M. Differential expression profiling of membrane proteins by quantitative proteomics in a human mesenchymal stem cell line undergoing osteoblast differentiation. Stem Cells 2005, 23, 1367-1377.

(11) Kratchmarova, I.; Blagoev, B.; Haack-Sorensen, M.; Kassem, M.; Mann, M. Mechanism of divergent growth factor effects in mesenchymal stem cell differentiation. Science 2005, 308, 1472-1477.

(12) Salasznyk, R. M.; Westcott, A. M.; Klees, R. F.; Ward, D. F.; Xiang, Z.; Vandenberg, S.; Bennett, K.; Plopper, G. E. Comparing the protein expression profiles of human mesenchymal stem cells and human osteoblasts using gene ontologies. Stem Cells Dev. 2005, 14, 354-366.

(13) Spreafico, A.; Frediani, B.; Capperucci, C.; Chellini, F.; Paffetti, A.; D’Ambrosio, C.; Bernardini, G.; Mini, R.; Collodel, G.; Scaloni, A.; Marcolongo, R.; Santucci, A. A proteomic study on human osteoblastic cells proliferation and differentiation. Proteomics 2006, 6, 3520-3532.

(14) Xiao, Z.; Camalier, C. E.; Nagashima, K.; Chan, K. C.; Lucas, D. A.; de la Cruz, M. J.; Gignac, M.; Lockett, S.; Issaq, H. J.; Veenstra, T. D.; Conrads, T. P.; Beck, G. R. Analysis of the extracellular matrix vesicle proteome in mineralizing osteoblasts. J. Cell. Physiol. 2007, 210, 325-335.

(15) Chiba, H.; Sawada, N.; Ono, T.; Ishii, S.; Mori, M. Establishment and characterization of a simian virus 40 -immortalized osteoblastic cell line from normal human bone. Jpn. J. Cancer Res. 1993, 84, 290-297. 
(16) Stoop, M. P.; Lamers, R. J.; Burgers, P. C.; Sillevis Smitt, P. A.; Hintzen, R. Q.; Luider, T. M. The rate of false positive sequence matches of peptides profiled by MALDI MS and identified by MS/ MS. J. Proteome Res. 2008, 7, 4841-4847.

(17) Wessel, D.; Flugge, U. I. A method for the quantitative recovery of protein in dilute solution in the presence of detergents and lipids. Anal. Biochem. 1984, 138, 141-143.

(18) Balgley, B. M.; Laudeman, T.; Yang, L.; Song, T.; Lee, C. S. Comparative evaluation of tandem MS search algorithms using a target-decoy search strategy. Mol. Cell. Proteomics 2007, 6, 1599-1608.

(19) Omenn, G. S.; States, D. J.; Adamski, M.; Blackwell, T. W.; Menon, R.; Hermjakob, H.; Apweiler, R.; Haab, B. B.; Simpson, R. J.; Eddes, J. S.; Kapp, E. A.; Moritz, R. L.; Chan, D. W.; Rai, A. J.; Admon, A.; Aebersold, R.; Eng, J.; Hancock, W. S.; Hefta, S. A.; Meyer, H.; Paik, Y. K.; Yoo, J. S.; Ping, P.; Pounds, J.; Adkins, J.; Qian, X.; Wang, R.; Wasinger, V.; Wu, C. Y.; Zhao, X.; Zeng, R.; Archakov, A.; Tsugita, A.; Beer, I.; Pandey, A.; Pisano, M.; Andrews, P.; Tammen, H.; Speicher, D. W.; Hanash, S. M. Overview of the HUPO Plasma Proteome Project: results from the pilot phase with 35 collaborating laboratories and multiple analytical groups, generating a core dataset of 3020 proteins and a publicly-available database. Proteomics 2005, 5, 3226-3245.

(20) Dennis, G.; Sherman, B. T.; Hosack, D. A.; Yang, J.; Gao, W.; Lane, H. C.; Lempicki, R. A. DAVID: Database for annotation, visualization, and integrated discovery. Genome Biol. 2003, 4, P3.

(21) Huang, D. W.; Sherman, B. T.; Lempicki, R. A. Systematic and integrative analysis of large gene lists using DAVID bioinformatics resources. Nat. Protoc. 2009, 4, 44-57.

(22) Mounkes, L. C.; Kozlov, S.; Hernandez, L.; Sullivan, T.; Stewart C. L. A progeroid syndrome in mice is caused by defects in A-type lamins. Nature 2003, 423, 298-301.

(23) Titulaer, M. K.; Mustafa, D. A. N.; Siccama, I.; Konijnenburg, M.; Burgers, P. C.; Andeweg, A. C.; Smitt, P. A. E. S.; Kros, J. M.; Luider, T. M. A software application for comparing large numbers of high resolution MALDI-FTICR MS spectra demonstrated by searching candidate biomarkers for glioma blood vessel formation. BMC Bioinf. 2008, 9.

(24) Titulaer, M. K.; Siccama, I.; Dekker, L. J.; van Rijswijk, A. L.; Heeren, R. M.; Sillevis Smitt, P. A.; Luider, T. M. A database application for pre-processing, storage and comparison of mass spectra derived from patients and controls. BMC Bioinf. 2006, $7,403$.

(25) Damsky, C. H. Extracellular matrix-integrin interactions in osteoblast function and tissue remodeling. Bone 1999, 25, 95-96.

(26) Brown, S. C.; Kruppa, G.; Dasseux, J. L. Metabolomics applications of FT-ICR mass spectrometry. Mass Spectrom.Rev. 2005, 24, 223231.

(27) Rompp, A.; Dekker, L.; Taban, I.; Jenster, G.; Boogerd, W.; Bonfrer, H.; Spengler, B.; Heeren, R.; Smitt, P. S.; Luider, T. M. Identification of leptomeningeal metastasis-related proteins in cerebrospinal fluid of patients with breast cancer by a combination of MALDITOF, MALDI-FTICR and nanoLC-FTICR MS. Proteomics 2007, 7, 474-481.

(28) Higuchi, C.; Nakamura, N.; Yoshikawa, H.; Itoh, K. Transient dynamic actin cytoskeletal change stimulates the osteoblastic differentiation. J. Bone Miner. Metab. 2009, 27, 158-167.

(29) Burridge, K.; Nuckolls, G.; Otey, C.; Pavalko, F.; Simon, K.; Turner, C. Actin Membrane Interaction in Focal Adhesions. Cell Differ. Dev. 1990, 32, 337-342.

(30) Hynes, R. O. Integrins-Versatility, modulation, and signaling in cell-adhesion. Cell 1992, 69, 11-25.

(31) Siebers, M. C.; ter Brugge, P. J.; Walboomers, X. F.; Jansen, J. A. Integrins as linker proteins between osteoblasts and bone replacing materials. A critical review. Biomaterials 2005, 26, 137-146.

(32) Carvalho, R. S.; Kostenuik, P. J.; Salih, E.; Bumann, A.; Gerstenfeld, L. C. Selective adhesion of osteoblastic cells to different integrin ligands induces osteopontin gene expression. Matrix Biol. 2003, 22, 241-249.

(33) Cowles, E. A.; Brailey, L. L.; Gronowicz, G. A. Integrin-mediated signaling regulates AP-1 transcription factors and proliferation in osteoblasts. J. Biomed. Mater. Res. 2000, 52, 725-737.

(34) Rosen, C. J. Bone remodeling, energy metabolism, and the molecular clock. Cell Metab. 2008, 7, 7-10.

(35) Komarova, S. V.; Ataullakhanov, F. I.; Globus, R. K. Bioenergetics and mitochondrial transmembrane potential during differentiation of cultured osteoblasts. Am. J. Physiol.: Cell Physiol. 2000, 279, C1220-1229.

(36) Chen, C. T.; Shih, Y. R.; Kuo, T. K.; Lee, O. K.; Wei, Y. H. Coordinated changes of mitochondrial biogenesis and antioxidant enzymes during osteogenic differentiation of human mesenchymal stem cells. Stem Cells 2008, 26, 960-968.
(37) Skjodt, H.; Moller, T.; Freiesleben, S. F. Human osteoblast-like cells expressing Mhc Class-II determinants stimulate allogeneic and autologous peripheral-blood mononuclear-cells and function as antigen-presenting cells. Immunology 1989, 68, 416-420.

(38) Calvi, L. M.; Adams, G. B.; Weibrecht, K. W.; Weber, J. M.; Olson, D. P.; Knight, M. C.; Martin, R. P.; Schipani, E.; Divieti, P.; Bringhurst, F. R.; Milner, L. A.; Kronenberg, H. M.; Scadden, D. T. Osteoblastic cells regulate the haematopoietic stem cell niche. Nature 2003, 425, 841-846.

(39) Yang, J. Y.; Jung, J. Y.; Cho, S. W.; Choi, H. J.; Kim, S. W.; Kim, S. Y.; Kim, H. J.; Jang, C. H.; Lee, M. G.; Han, J.; Shin, C. S. Chloride intracellular channel 1 regulates osteoblast differentiation. Bone 2009, 45, 1175-1185.

(40) Rostovtseva, T.; Colombini, M. VDAC channels mediate and gate the flow of ATP: Implications for the regulation of mitochondrial function. Biophys. J. 1997, 72, 1954-1962.

(41) Balcerzak, M.; Malinowska, A.; Thouverey, C.; Sekrecka, A.; Dadlez, M.; Buchet, R.; Pikula, S. Proteome analysis of matrix vesicles isolated from femurs of chicken embryo. Proteomics 2008, 8, 192205.

(42) Anderson, H. C. Molecular-Biology of Matrix Vesicles. Clin. Orthop. Relat. Res. 1995, 266-280.

(43) Anderson, H. C.; Garimella, R.; Tague, S. E. The role of matrix vesicles in growth plate development and biomineralization. Front. Biosci. 2005, 10, 822-837.

(44) Moursi, A. M.; Najafi, M.; Globus, R. K.; Damsky, C. H. Integrinfibronectin interactions are critical for osteogenesis and osteoblast differentiation. J. Dent. Res. 1997, 76, 2261-2261.

(45) Globus, R. K.; Doty, S. B.; Lull, J. C.; Holmuhamedov, E.; Humphries, M. J.; Damsky, C. H. Fibronectin is a survival factor for differentiated osteoblasts. J. Cell Sci. 1998, 111, 1385-1393.

(46) Gillette, J. M.; Nielsen-Preiss, S. M. The role of annexin 2 in osteoblastic mineralization. J. Cell Sci. 2004, 117, 441-449.

(47) Kirsch, T.; Harrison, G.; Golub, E. E.; Nah, H. D. The roles of annexins and types II and X collagen in matrix vesicle-mediated mineralization of growth plate cartilage. J. Biol. Chem. 2000, 275, 35577-35583.

(48) Menaa, C.; Devlin, R. D.; Reddy, S. V.; Gazitt, Y.; Choi, S. J.; Roodman, G. D. Annexin II increases osteoclast formation by stimulating the proliferation of osteoclast precursors in human marrow cultures. J. Clin. Invest. 1999, 103, 1605-1613.

(49) Takahashi, S.; Reddy, S. V.; Chirgwin, J. M.; Devlin, R.; Haipek, C.; Anderson, J.; Roodman, G. D. Cloning and identification of annexin II as an autocrine/paracrine factor that increases osteoclast formation and bone resorption. J. Biol. Chem. 1994, 269, 28696-28701.

(50) Pendas, A. M.; Zhou, Z. J.; Cadinanos, J.; Freije, J. M. P.; Wang, J. M.; Hultenby, K.; Astudillo, A.; Wernerson, A.; Rodriguez, F.; Tryggvason, K.; Lopez-Otin, C. Defective prelamin A processing and muscular and adipocyte alterations in Zmpste24 metalloproteinase-deficient mice. Nat. Genet. 2002, 31, 94-99.

(51) Rodrigues, G. H. D.; Tamega, I. D.; Duque, G.; Neto, V. S. D. Severe bone changes in a case of Hutchinson-Gilford syndrome. Ann. Genet. 2002, 45, 151-155.

(52) Bank, R. A.; Robins, S. P.; Wijmenga, C.; Breslau-Siderius, L. J.; Bardoel, A. F. J.; Van der Sluijs, H. A.; Pruijs, H. E. H.; TeKoppele, J. M. Defective collagen crosslinking in bone, but not in ligament or cartilage, in Bruck syndrome: Indications for a bone-specific telopeptide lysyl hydroxylase on chromosome 17. Proc. Natl. Acad. Sci. U.S.A. 1999, 96, 1054-1058.

(53) Naito, Y.; Lowenstein, J. M. 5'-Nucleotidase from rat heart. Biochemistry 1981, 20, 5188-5194.

(54) Buhring, H. J.; Battula, V. L.; Treml, S.; Schewe, B.; Kanz, L.; Vogel, W. Novel markers for the prospective isolation of human MSC. Ann. N.Y. Acad. Sci. 2007, 1106, 262-271.

(55) Dominici, M.; Le Blanc, K.; Mueller, I.; Slaper-Cortenbach, I.; Marini, F. C.; Krause, D. S.; Deans, R. J.; Keating, A.; Prockop, D. J.; Horwitz, E. M. Minimal criteria for defining multipotent mesenchymal stromal cells. The International Society for Cellular Therapy position statement. Cytotherapy 2006, 8, 315-317.

(56) Hughes, R. C. Galectins as modulators of cell adhesion. Biochimie 2001, 83, 667-676.

(57) Scott, K.; Weinberg, C. Galectin-1: A bifunctional regulator of cellular proliferation. Glycoconjugate J. 2002, 19, 467-477.

(58) Perillo, N. L.; Pace, K. E.; Seilhamer, J. J.; Baum, L. G. Apoptosis of T-cells mediated by galectin-1. Nature 1995, 378, 736-739.

(59) Chan, J.; O’Donoghue, K.; Gavina, M.; Torrente, Y.; Kennea, N.; Mehmet, H.; Stewart, H.; Watt, D. J.; Morgan, J. E.; Fisk, N. M. Galectin-1 induces skeletal muscle differentiation in human fetal mesenchymal stem cells and increases muscle regeneration. Stem Cells 2006, 24, 1879-1891. 
(60) Dekker, L. J.; Burgers, P. C.; Guzel, C.; Luider, T. M. FTMS and TOF/ TOF mass spectrometry in concert: Identifying peptides with high reliability using matrix prespotted MALDI target plates. J. Chromatogr., B: Anal. Technol. Biomed. Life Sci. 2007, 847, 62-64.

(61) Schmid, A. K.; Lipton, M. S.; Mottaz, H.; Monroe, M. E.; Smith, R. D.; Lidstrom, M. E. Global whole-cell FTICR mass spectrometric proteomics analysis of the heat shock response in the radioresistant bacterium Deinococcus radiodurans. J. Proteome Res. 2005 $4,709-718$.
(62) Page, J. S.; Masselon, C. D.; Smith, R. D. FTICR mass spectrometry for qualitative and quantitative bioanalyses. Curr. Opin. Biotechnol. 2004, 15, 3-11.

(63) Anderson, N. L.; Anderson, N. G. Proteome and proteomics: New technologies, new concepts, and new words. Electrophoresis 1998, 19, 1853-1861.

(64) Rappsilber, J.; Mann, M. What does it mean to identify a protein in proteomics. Trends Biochem. Sci. 2002, 27, 74-78.

PR100400D 